\title{
A Web Based Approach: Smart E- Ration shop using two way Authentication System
}

\author{
G. Divya ${ }^{1}$, M. Ranjani ${ }^{2}$, Dr. D. Preetha Evangeline ${ }^{3}$ \\ ${ }^{1}$ SRM Institute of Science and Technology, India, divyag2@ srmist.edu.in \\ ${ }^{2}$ SRM Institute of Science and Technology, India, ranjanim1@ srmist.edu.in \\ ${ }^{3}$ Vellore Institute of Technology, India, preetha.evangeline@vit.ac.in
}

\begin{abstract}
Public Distribution System (PDS) is responsible for distributing food grain to poor people of India. It was founded by the central government of India under the Ministry of Consumer affairs, Food and Public Distribution. State and central government equally responsible for PDS. Central government is responsible for major work like transportation, storage etc. While state government is responsible for ration card allocation, validation and distribution of food grains. As per NFSA rule, mainly two types of ration cards are provided Antyodaya and PRC (Priority Ration Card). The Antyodaya card holder is allowed $35 \mathrm{~kg}$ of food grains per month and the PRC card holder 5 grams per month per member. The main disadvantages of current system is that Dealers get lower salaries so they hold the many fake ration cards using this they sell the food grain to open market and also sometimes dealers swap the good quality food grains to low quality food grains. To report these fraudulent activities, there is no proper feedback system .There is also problems such as to handle hard cash, manual entry, no shop availability monitoring etc. So to overcome with all these problems this system implements E-ration shop which helps in avoiding corruption and black marketing in PDS. E-Ration shop is web application using this web Application ration card holder can check the shop availability, check his previous purchase details, available food grain, and market price rate of food grain and can make online add or remove member request.
\end{abstract}

Key words: Public Distribution System, Ration card, One Time Password, Smart Card.

\section{INTRODUCTION}

Public Distribution System is an important program run by the government of India to maintain the food security of India. The central and state government shares responsibility of regulating the PDS. While the Central government responsible for storage, bulk allocation and transportation, State government is responsible for distributing the grains and also the allocation and validation of ration cards. Government distributes wheat, rice and sugar to poor people at low price which are provided to the customers through ration shops. These ration shop are open by government at village level or area wise and each shop is allocated under one dealer who is responsible to sell the food grain and make the entry of sell. The food grain for these ration shops will be purchased directly from the farmers and sold at lower price to people. Fresh stock arrives at these stores every month and needs to be distributed to the public.

For any purchase customer need a valid ration card, There are several type of ration card like Antayodaya, PRC(Priority ration cards) people who are below poverty line are given $35 \mathrm{~kg}$ of food grain per month while people above poverty line card holder will get $5 \mathrm{~kg}$ food grain per month per member. But efficiency and effectiveness of PDS is always a major issue. There are several problems of current system like dealer swap the good quality food grain with the low quality stock, Black marketing of food grains, bogus ration cards, and validation of valid ration card holder. To resolve all these problems this system is developed that helps to make system more efficient and effective.

\section{RELATED WORK}

PDS protect the Food Security system of India and because it benefits the huge population of India by providing the food grains at lower price rates. So System should be more efficient, fraud less and free from the corruption. But there is always a problem of forgery, food swapping and back marketing in food grain distribution .So PDS System is always at the center of research and innovative ideas.

The PDS should be restructured and there is a desire to examine the prospect of proposing inventive concepts like Smart ration cards to eradicate starvation an. To prevent corruption and black marketing there are many methods and research has been published such as Introducing the Finger print to verify that whether the customer is valid ration card holder or not, Using the Automatic weighing machine to measure the weight of food grain at time of purchase it require 
no manual intervention and system are design to store the sell details by dealer so that government can easily monitored the transactions.

Vikram Singh [1] et al described a Smart card ration distribution system in which Bio metric is used as unique identity verification for customer. Every customer holds a smart card that has printed with Head of House name, Ration card Number and Bar Code that can be used for transaction. So to use this facility each customer need to register by filling all his details and submitting income certificate and aadhar card details these details are used by the government authority to check the request is valid or not. If request is valid accepted by the authority and one smart card will be created and send through the post to customer.

S.D.Thorat, Kharade Supriya Ashok, Taware Pradanya [2] described the automatic ration distribution system. In his system each customer need to go through online registration he has to give all the details of him and his family, applicant should opt for the Head of family from the family members. After registering unique id and password will be created that password is used to verify the customer for purchase process. By entering the details on dealer system customer can login purchase can be done and sell details will be stored in database. This system has advantage that any family member can collect the food grain from shop by knowing the password and id, but this system is not more secure if the password is stolen anyone can perform the transaction.

Aishwarya Pachpute, Pooja Bisukarma [3] implemented the Bachat gat System to use this system each customer first need to register to the website by providing Valid Id, ration card number and mobile number family details. After registering customer will be given unique id and password. At the time of purchase the customer need to enter the unique id to dealer system and one OTP sent to registered mobile number, Now Customer need to enter that OTP if entered OTP is valid the customer is proceed for purchase and online receipt will be generated. The main drawback of this system is that there is no shop availability monitoring and online payment system.

Prasana Balajir, Manikandan [4] implemented software based solution for PDS. It is developed in $\mathrm{C}, \mathrm{C}++$. The main features of this software are Stock availability monitoring and purchase through online system. For this system each customer need to register on this software after register they will be given user id and password. At time of purchase customer needs to login at dealer System and there are four option are available on portal Item Status (total quantity available and quantity available for customer), Rate of Food grains, Purchase by clicking on this purchase can be done and last is sign out. This system is not enough to solve the issue of PDS. It does not have security, no customer validation at time of purchase any one can use any ones id and password can process for purchase. There is no feedback system from customer. So this system just automates the purchase process but does not remove the drawbacks of PDS.

Jinali Goradia, Sarthak Doshi [5] focus more on Automatic weighing of Food grains for this they have suggested a Embedded solution. In this suggested machine one display will be given by that quantity and customer id can be entered by either customer or dealer and after entering place the container inside the valve, valve will get open automatically and food grain started falling in container and weight start increasing display when it reach the weight entered valve get closed after valve closed details of purchase are stored in database.

Dhanashri Pingale, Sonali Patil [6] introduced a web based solution for PDS. They have used finger print and aadhar data to validate the customer. Because they have used an aadhar card for validation so there cannot be bogus ration card are possible. In this system they have given features such as, monitoring of shop is given so customer can check his shop is open or closed on online portal, also adding or removing member is automated online application can be made and document uploaded are used for validity so there is no manual intervention. But there is no online payment system so there is problem of handling hard cash and there is no feedback system so customer can report problem to government authority.

\section{PROPOSED WORK}

In this system Double OTP SMS system, One OTP for the Customer validation and other OTP are used for the Payment Process. Here, first customer need to register to our system by giving all the details such as family member details, aadhar card number, documents like Income certificate etc. After registration customer will get one user id and password and after some time E-Smart card will be generated for customer. One OTP is sent at time of Grain allocation by government authority, this is used at time of purchase to validate the customer. When Customer login he/she can use the features like Add Member, Remove member, check the Shop availability and also the last purchased receipt. On other side dealer will get features like Generate e-receipt, sale stats and can also give the feedback for any bad service. Similarly on Government authority side will be features such as Add/ remove member requests, Grain allocation and feedback and sales stats etc.

Figure 1 explains in detail about the technical architecture of Web Application through the following steps:

1. In current system to add member, remove or change address customer need to go through manual process of filling form and submit details to district level officer but here we have implemented a module in which customer can apply online and upload the valid documents 
these documents can be used by the government authority to verify the details .Here customer can check the continuously status of his request either it is pending, accepted or rejected.

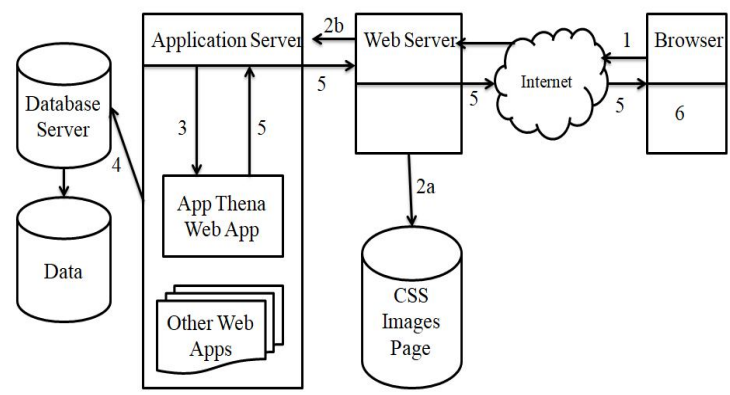

Figure 1: Technical Architecture of Web Application

2. FPS Ration shops not open every day, when they will open there is no proper fixed timing. So there this is always big issue for customer to know whether the shop is closed or open. But in our website customer can check the status of its shop by just entering its dealer id. This will also send a SMS to each customer under particular dealer whenever the shop is closed or open. This make system more efficient and less time consuming .It decrease the manual intervention.

3. The food processing system manager has to maintain the register and the food department has to spend a lot of time to submit the data. Food processing managers has to maintain various types of details such as number of card holder and amounts of food grains purchased and estimated inventory for next purchase, and many other periodic, cumulative figures. But in our system all the purchase details and food grain allocation is updated automatically on website that can be viewed by any authority.

4. In current system if there is any problem such as quality or quantity of food grains customer cannot report directly to authority but here in our system we have implemented one feedback system after each purchase customer will get one SMS with one link so just by clicking on link customer can give his feedback. Because in rural areas people are not much educated. Those people can give his feedback by seeing image and selecting checkbox.

5. In PDS every month new stock of food grain will be made available to every dealer but each month not all customer buy food grains, so there is always some quantity of food grain left on Shop so in current there is no proper measure to monitor available quantity. But in our system at the time of Food grain allocation it is visible for authority that particular dealer is left with this much amount of food grains and how much he needs for this month.

Figure 2 represents the application architecture of proposed system. This system has five menus Home, Search, Quick Link, Information, and $\operatorname{login} /$ SignUp.

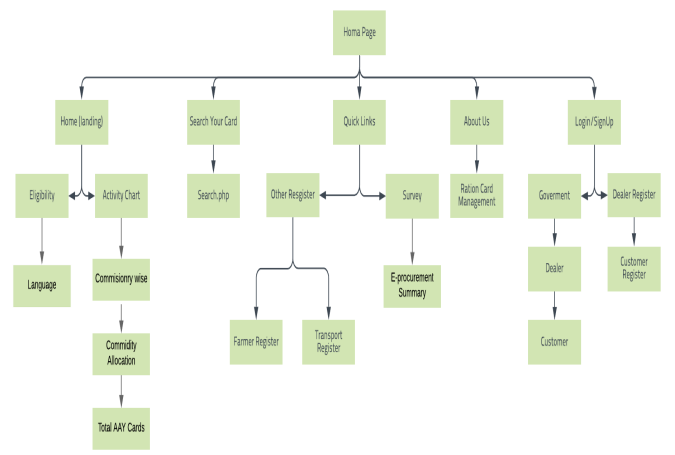

Figure 2: Application Architecture of Proposed System.

\section{E - RATION SYSTEM}

Figure 3 represents an Information flow, input and output of information in the system. It is used to represent the flow of information between users, Data Unit and Process. By describing the data flow it describe the functionality of System. It is widely used in Software industry to explain data transformation between systems.

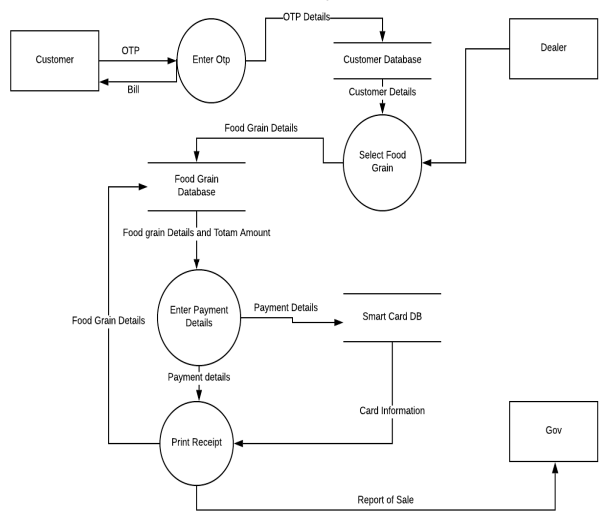

Figure 3: Work Flow

\section{Algorithm for E-Ration}

In Figure 4, the E-Ration system flow is explained through this algorithm.

Step 1: Gov authority Enter into system and login with credential. 
Step 2: Click on the Food Grain Allocation Menu of web system

Step 3: Enter the dealer id that he wants to allocate a food grain and then click on submit.

Step 4: After click submit new page will open where previous month available food grain and requirement for this month will be visible for particular dealer, now by entering the month id authority submit the form.

Step 5: When he click on submit button all the customer under that dealer will get a SMS with OTP.

Step 6: Now After receiving Food grain Dealer open a shop and login into system.

Step 7: When Customer reach the shop and ask for purchase, Dealer Click on generate E-receipt menu and Customer tell the OTP to Dealer by entering OTP and click on validate System validate the Customer either he/she is valid beneficiary or not.

Step 8: After clicking on Validate button Non editable form will be open where the quantity allowed to that customer will be displayed.

Step 9: Dealer click on the submit details button and this will transfer him to Payment Option Where form will open and it needs the Smart card details of Customer.

Step 10: Now by entering smart card details and submit form OTP will be sent to customer, that OTP required to Complete the transaction .

Step 11: Next step dealer enter the OTP and online receipt automatically will be generated.

\section{Algorithms for Transaction}

Step 1: Start

Step 2: Enter the Dealer Login Id and Password

Step 3: If entered user id and password is valid then goto Step 4

Else

Re-enter dealer username and password End if

Step 4: Customer Enter the OTP

Step 5: If OTP is valid and match with database goto step 6

\section{Else}

Show message please enter valid OTP End If

Step 6: Food grain material will be visible

Step 7: Dealer enter the Month id and submit the details

Step 8: Directed to payment Gateway

Step 9: Form will be open ask for customer for customer details

Step 10: Either customer or dealer enter all the details and submit the form Now Dealer directed to next page for OTP validation

Step 11: After click on Submit button One Time password will be generated and sent customer mobile number.

Step 12: Now either customer or dealer will enter the otp to system.

Step 13: If OTP is valid then go to step 14

Else
Error message will be popped up to enter the valid one time password.

End if

Step 14: Online Receipt will be generated and purchase details will be stored in database.

Step 15: Print Copy of receipt hand over to customer.

Step 16: End the process.

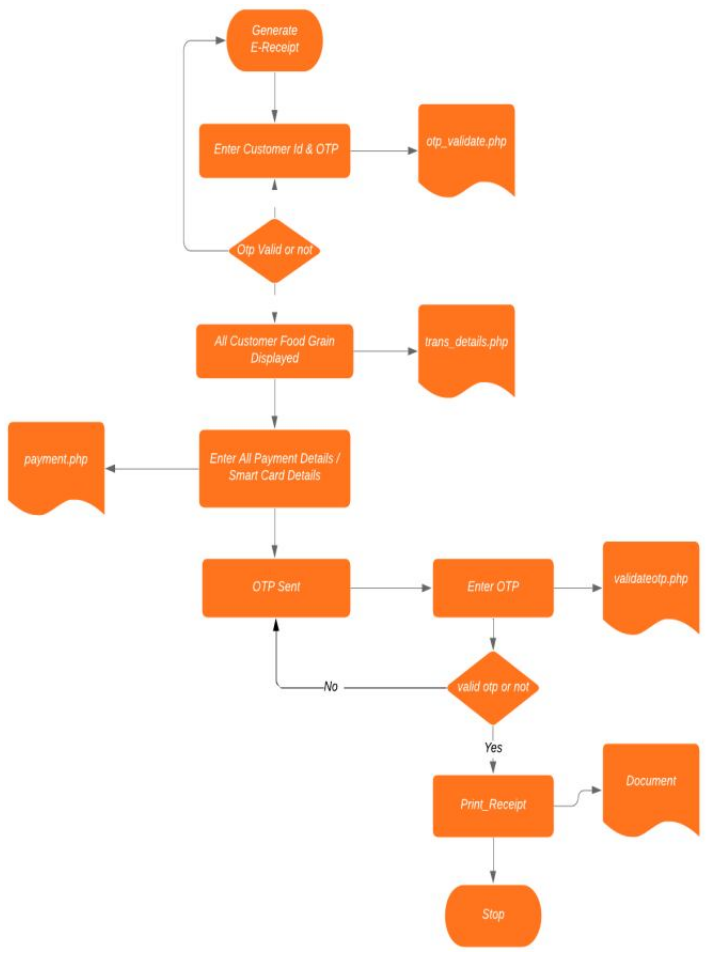

Figure 4: System Overview

\section{RESULTS AND DISCUSSION}

\section{Database Creation}

This part of implementation involves the creation of database that name as major with various table like food grain, gov_otp, total_sale, smart_card, feedback. These tables are used to fetch and store the record in the database.

- Customer ( cid, name, father, mother, aadhar, mobile, address, district, pincode, password, card type)

- Dealer ( dealer id, name, mobile, email, password, address, shop id)

- $\quad$ Sales ( month, sugar, rice, wheat)

- Total sales ( cid, month, did, sugar, rice, wheat)

- Food grain ( did, month, sugar, rice, wheat)

- Login ( user, status)

- Gov_otp (cid, OTP)

- Feedback ( cid ,feedback)

- Upload files ( cid, app_name, did, mobile, aadhar, member, dob, aadhar, proof) 


\section{Front_End Design}

Front end design is responsible for user interaction to system and gives input to system. Front end play a major role in system so it should be smooth in design and responsive with device. Here to design front end or web pages we have used the HTML to describe the structure the web page and CSS used to give the colors and java script to provide web page a dynamic interaction. Bootstrap is framework that uses HTML, CSS for design a responsive web page. These are below some functionality for which web pages has been designed:

- Grain Allocation from government side.

- Customer validation

- Display All Customer details with Food grain details

- Payment Gateway to Input Card details

- Online Receipt

- Front page (Combine all module and give link for login and registration for each module, also consist of Charts to show sales etc.)

- Various registration forms

- Customer Feedback form

\section{Back_End Development}

Back end development involves writing script that used to link the web pages with data base; it is responsible for transfer input to DB and fetches the result from database based on user command and display on web pages. It is used for behind the scenes activities that happen on when performing action on website. Here for back end side development we have used PHP. PHP is server side scripting side language and it is used for both static and dynamic web site development.

- These are some feature for which we have creates PHP scripts such as:

- Data base connectivity

- Fetch the details from database.

- To insert the details to database.

- To Update or delete the database record.

- Script to Validate Login Credential of Users.

\section{SMS Gateway}

In this system, to sent OTP or Feedback SMS to customer we need SMS Service, for this, TextLocal sms Gateway is used. Here we need to create one API from website user interface and need to implement in our system to perform the SMS related task. After this, a Controller class is created to perform messaging service.

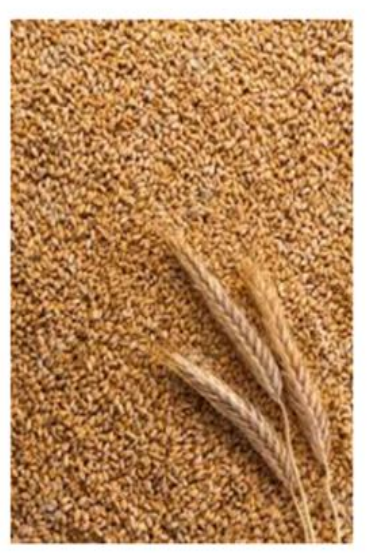

\section{Customer Details}

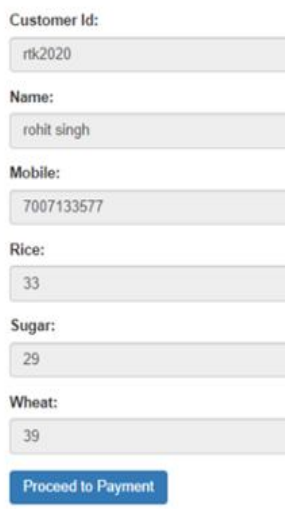

Figure 5: Grain Allocation Page
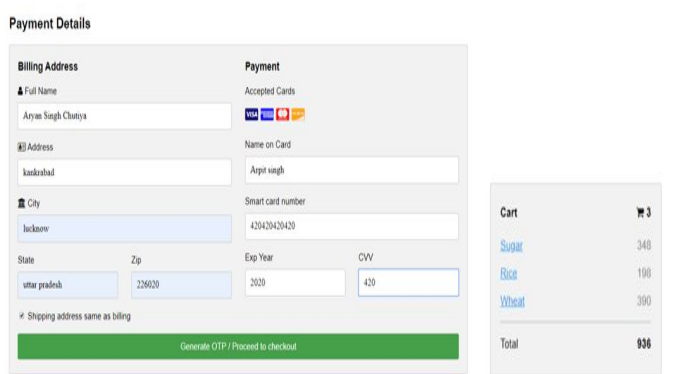

Figure 6: Payment Page

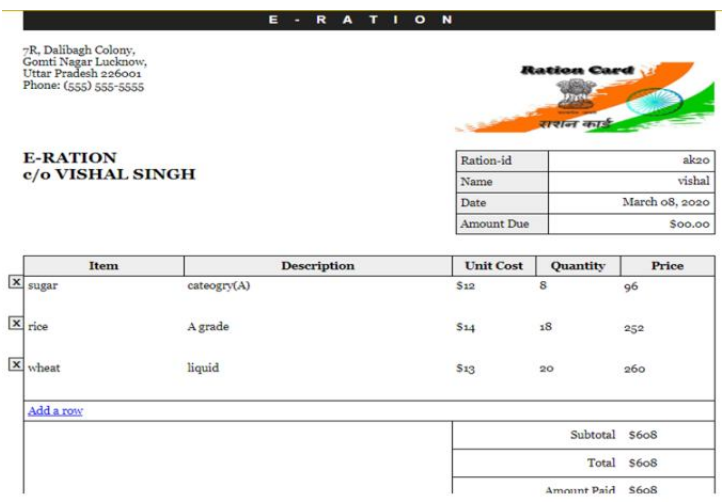

Figure 7: Receipt

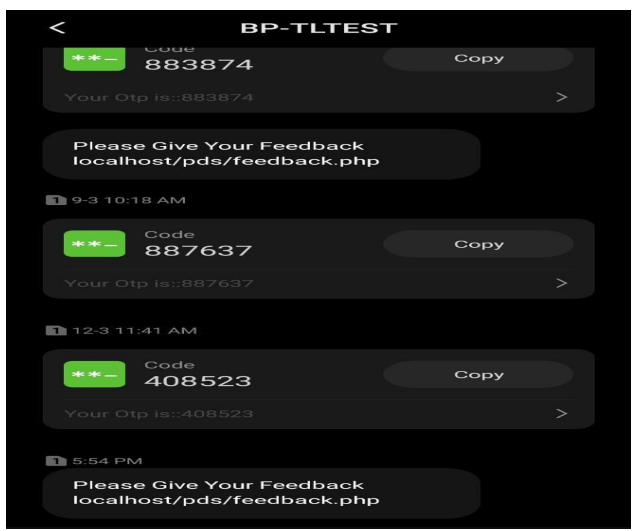

Figure 8: SMS to Customer 


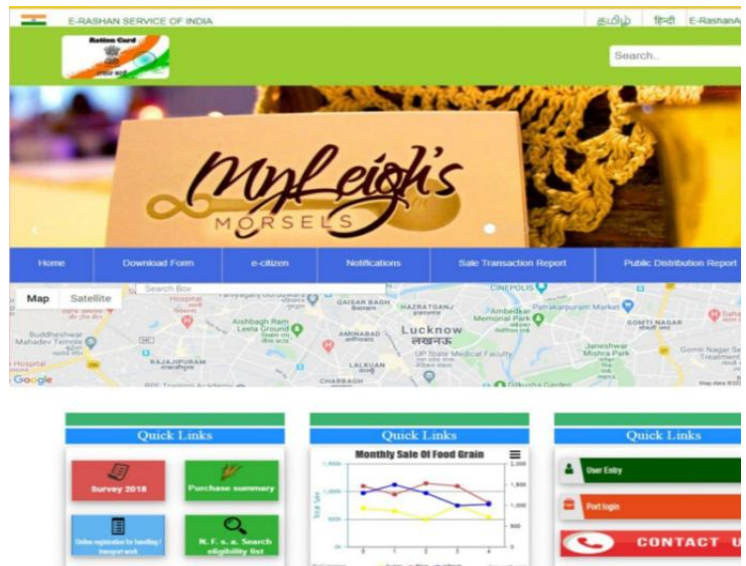

Figure 9: Home Page of System.

\section{CONCLUSION}

Food swapping, Black marketing and fraud ration cards are biggest challenge that food distribution system faced. So there is always a situation that either some customer will get low quantity or low quality food grain, because PDS System serves huge population of India it should be free from corruption and be more effective .So here it is able to deal with these problems and provide more efficient solution for PDS. Fallacious input to Ration Shop database can be avoided with the use of smart ration cards and more security is given by the double OTP Verification. The dealer is only responsible for selecting the quantity of the food grains, where as amend and deducting is solely handled by the server (food department).Making Payment through smart card remove the drawbacks of Hard Cash. Providing the e-receipt of purchase removes the use of paper pen in PDS. It also provides the customer update of his shop status thorough a SMS. All the Application such as Add member / Remove member can be done from this website. It also provides more transparency and effectiveness to PDS.

\section{FUTURE WORK}

System can be made available in various local languages. Automatic machine for weighing commodities can be implemented. Machine learning algorithm can be implemented in government authority side to categorize the feedback of customer. Database and security of system can make more secure. Mobile application can also develop for the system. Food grain tracking tools can be provided. Shop Availability module can be enhanced. Login module can be implemented through OTP.

\section{REFERENCES}

[1] S.V.S Prasad, T. Vijetha, A. Sudhakar, M. Raju Naik "Smart Ration Card System using Lab View," International Journal of Engineering and
Advanced Technology (IJEAT), ISSN: $2249-$ 8958, Vol. 9 Issue 2, December, 2019.

[2] S.D.Thorat, Kharade Supriya Ashok, Taware Pradanya, "E-Ration Distribution System Based on QR- Code," International Journal for Scientific Research and Development, pp. 153154, Vol. 6, Issue 9, December 2018.

[3] Aishwarya Pachpute, Pooja Bisukarma, Aishwarya S. Awate, Amrut V. Kanade, "Smart Ration Card System using OTP," Journal of Emerging Technologies and Innovative Research, ISSN 2349-5162, Vol. 6, Issue 2, February 2019.

[4] Prasana Balajir, Manikandan T, "Automatic Public Distribution System," International Journal of Computer Science and Mobile Computing, Vol. 2, Issue. 7, PP. 93-107, July 2013.

[5] Jinali Goradia, Sarthak Doshi, "Automated Ration Distribution System," International Conference on Advanced Computing Technologies and Application, pp 528-532, December 2015.

[6] Dhanashri Pingale, Sonali Patil, Nishigandha Gadakh, Reena Avhad, Gundal S.S "Web Enabled Ration Distribution and Corruption Controlling System", International Journal of Engineering and Innovative Technology (IJEIT), Volume Issue 8, February 2013.

[7] Shivbhakt mhalsakant Hanmant, Suraj V.S, Moresh Mukhedkar, "Automization of Rationing System", International Journal of Computational Engineering \& Management (IJCEM), Volume 7, Issue 6, November 2014.

[8] Rajesh C. Pingle and P. B. Borole,"Automatic Rationing for Public Distribution System (PDS) using RFID and GSM Module to Prevent Irregularities," HCTL Open International Journal of Technology Innovations and Research, vol 2, pp.102-111, March 2013

[9] T.R.Sreenivas, "A case of supply chain management of Public Distribution System operations in the Chhattisgarh state of India", 3 - 7 September 2012.

[10] Ankit Lodha, "Clinical Trial Analytics: Fulfilling the Future of Clinical Operation Insights," Imperial Journal of Interdisciplinary Research, Vol. 3, Issue-1, 2016.

[11] S.Sukhumar, K.Gopinathan, S.Kalpanadevi,, P.Naveenkumar, N.Suthanthira Vanitha, "Automatic Rationing System Using Embedded System Technology", International Journal of Innovative Research in Electrical, Electronics, Instrumentation and Control Engineering, Vol. 1, Issue 8, November 2013. 